\title{
Jogging at CHI
}

\section{Florian 'Floyd' Mueller}

Exertion Games Lab

RMIT University

Melbourne

Australia

floyd@exertiongameslab.org

\section{Joe Marshall}

Mixed Reality Lab

University of Nottingham

Nottingham, UK

joe.marshall@nottingham.ac.uk

\section{Rohit Ashok Khot}

Exertion Games Lab

RMIT University

Melbourne

Australia

rohit@exertiongameslab.org

\section{Stina Nylander}

Mobile Life@SICS

Box 1263, a6429 Kista, Sweden

stny@sics.se

\section{Jakob Tholander}

Mobile Life@Stockholm University Forum 100, 16440, Kista, Sweden

jakobth@dsv.su.se

Permission to make digital or hard copies of part or all of this work for personal or classroom use is granted without fee provided that copies are not made or distributed for profit or commercial

advantage and that copies bear this notice and the full citation on the first page. Copyrights for third-party components of this work must be honored. For all other uses, contact the Owner/Author.

Copyright is held by the owner/author(s).

CHI'16 Extended Abstracts, May 07-12, 2016, San Jose, CA, USA ACM 978-1-4503-4082-3/16/05.

http://dx.doi.org/10.1145/2851581.2886435

\section{Abstract}

$\mathrm{HCI}$ is increasingly paying attention to sports, and more and more $\mathrm{CHI}$ attendees are aiming to maintain being physically active while attending $\mathrm{CHI}$. In response, we offer a SIG on the topic of sports-HCI and conduct it in a sportive way: we will go out of the conference venue and jog around San Jose while discussing the role of $\mathrm{HCI}$ in relation to sports. The goal is to actively shape the future of the field of sports-HCI.

\section{Author Keywords}

Sport; exercise; exertion

\section{ACM Classification Keywords}

H.5.2. [Information Interfaces and Presentation]: User Interfaces.

\section{Introduction}

$\mathrm{HCI}$ is increasingly paying attention to sports and an active lifestyle and in consequence the field of sports$\mathrm{HCI}$ has emerged in recent years [10]. Industry is also facing sports-HCI challenges through mobile apps such as targeted towards joggers with an aim to support an active lifestyle. Meanwhile various research projects examine new ways of supporting people being physically active through the use of novel systems, for example using quadcopters to support jogging

experiences [8]. Furthermore, game companies are exploring the use of gaming consoles to support indoor physical activity. 
The growth of sports-HCI as a field is attributed to the fact that the supporting technologies are getting cheaper and more accessible with each coming day, allowing even non-athletes to engage with such services. It is however noteworthy to see a balanced focus of these interactive systems that not only aim to support the performance aspect of the exertion activity, but also aim to harness experiential qualities of the exertion activity [12].

We believe sports-HCI deserves dedicated research efforts and therefore attention at $\mathrm{CHI}$ because an exerting participant inhibits a different cognitive and most importantly bodily state when interacting with technology, quite unlike general HCI that often focuses on point control systems. As such, the technology to support such participation needs to be designed differently. Unfortunately, our knowledge of how to design these interactive systems is still limited. Prior work points out that considering exertion when interacting with technology has its challenges [1] but also offers opportunities [2-5, 7]. Yet there is a gap in the form of a coherent understanding of how interaction designers should engage with sports-HCI.

This SIG aims to contribute to this understanding by bridging the gap and bridging together practitioners and academics interested in the field of sports-HCI. However, unlike regular SIGs, we engage participants by jogging as a group during a scheduled timeslot at $\mathrm{CHI}$ in San Jose. If participants want, they can bring along any technology they are currently developing as part of their research to be used during the jog. Our goal is to engage participants in the topic of sports-HCI by being in an active bodily state and hence we conduct a SIG that combines sports with research in an active way: by going jogging at $\mathrm{CHI}$.

Jogging at $\mathrm{CHI}$ is not new: we have conducted such a SIG since 2013. We had a total of 49 participants jogging, sometimes in the rain. Participants enjoyed that they were able to leave the conference venue behind for a while to get some fresh air yet still engage in research discussions. The participants said that the jogging activity supported their research thinking through moving around, which contrasts the typical $\mathrm{CHI}$ sitting-experience. Participants also appreciated that the outdoor environment appeared to facilitate different kinds of interactions with other CHI attendees. They also welcomed that the SIG offered a healthy way of engaging with $\mathrm{CHI}$ (contrasting the typical eating- and drinking-focused $\mathrm{CHI}$ experience). Most importantly, participants noted that discussing sports and $\mathrm{HCI}$ was furthered by the fact that they were exercising at the same time, suiting the SIG.

\section{Approach to conducting the SIG}

The call for SIGs at CHI 2016 asks for "creative approaches to conducting the SIG itself". We respond by suggesting leaving the $\mathrm{CHI}$ conference venue and actively engaging in jogging "in the wild" [11]. We begin by assembling everyone in the designated room, having changed into jogging gear beforehand in the break or at the beginning of the SIG in the nearby hotels or washroom facilities of the conference venue. We would appreciate a student volunteer to look after any bags. We then describe the jogging route and introduce group leaders (based on target pace) while also arranging proposed discussion topics. We currently envision discussion topics such as sports apps, fitness wearables, interactive performance clothing, exercise 
games, augmented gyms, rehabilitation systems and athlete-robot interaction. The route is determined beforehand through Google Maps but also through crowdsourced data such as facilitated by Runkeeper. We appreciate the SIG to be scheduled at the end of the second or third day of the conference, so that participants can go back to their respective hotels easily to have a shower and prepare for any evening activities.

This format worked well during the last three year's jogging sessions. We did have some rain previously, yet participants were still eager to go jogging.

Nevertheless, we acknowledge that weather is a risk for this SIG. However, the average weather in San Jose at this time of the year is favorable for jogging.

Many $\mathrm{CHI}$ attendees are already incorporating physical activity in their daily lives and many of them jog. Informal feedback from previous $\mathrm{CHIs}$ highlighted to us that they not only miss their opportunities to go jogging during $\mathrm{CHI}$, but they also find the continuous sitting during $\mathrm{CHI}$ exhausting and not inductive to good health. In response, many of them go to the gym in their hotel (with some hotels even offering complementary sports shoes to borrow). We aim to utilize this by combining it with research discussions about this emerging topic of sports-HCI while engaging in a sports activity itself. This matches prior work that suggests that interaction designers should move when designing for movement $[2,6,7]$.

\section{Participants}

Our targeted participants are practitioners and academics interested in the intersection between sports and HCI. This includes developers of sports apps, researchers of smartwatch sport uses, but also designers of games that support exertion activities with game consoles that sense physical activity such as the Kinect camera.

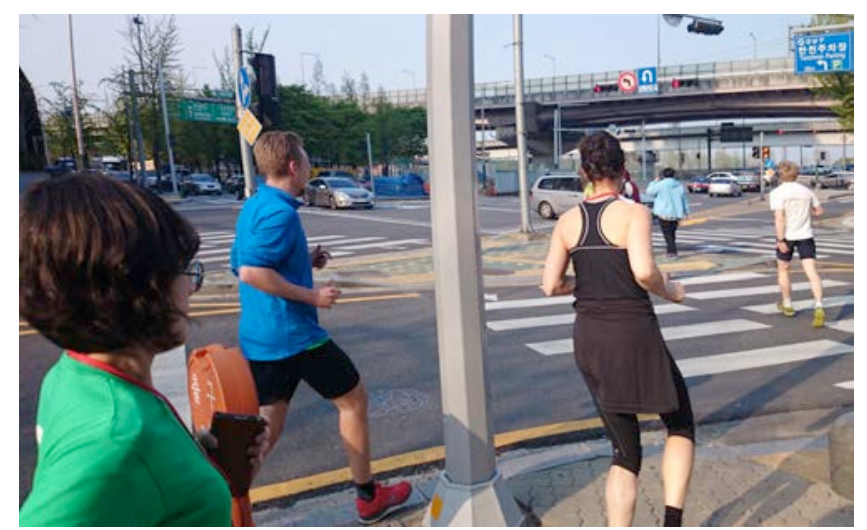

Figure 1. Photo of jogging at $\mathrm{CHI}^{\prime} 15$ in Seoul, Korea.

\section{Attendee background}

In the two prior years our joggers' experience varied significantly, yet we were able to accommodate all of them: we had figured out a jogging route through the use of Google Maps and then ran along it the day before the conference. Through this, we designed a path that slower joggers would run once, but faster ones would run multiple times. This allowed participants to talk to each other at different stages of the jog. In the first year, we also had people powerwalking, which also worked fine. If people have different abilities that would not be covered by this approach, they can contact us and we will aim to consider this through a dedicated strategy. 


\section{Approach of the SIG}

As with previous years, the SIG will be promoted through the $\mathrm{CHI}-$ Announcement mailing list. We will highlight that participants will need to bring jogging gear. We also encourage bringing along any research projects they might be working on and any technologies they are using during their current jogging activities. When everyone assembles in the dedicated room at $\mathrm{CHI}$, we will examine any brought-along technologies and any topics the participants want to discuss. We will also prepare topics, based on our combined expertise in this area, and propose them for attendees to chose from. Depending on the amount of topics that are proposed, we will lightly manage the speed of discussions during the jog. We will also aim to manage the discussions in terms of faster and slower participants, so that faster participants will meet up with slower participants during subsequent jogging rounds so they can experience a range of discussions.

At the conclusion of the jog, we will invite all participants back into the conference room. We will capture major themes that emerged and distribute any data we collected, including pictures, with participants' consent. During the stretching after the jog we will discuss further plans for jogging at $\mathrm{CHI}$ as well as how to bring sports-HCI forward as a field, such as conducting another workshop like the one we held last year [9] and the "interactions" magazine special article series [10] we organized previously. We are also considering a journal special edition on the topic. We draw on our past experiences with the fact that a heightened state of arousal as a result of exertion was conducive to social interaction [13] to fuel these discussions. Ultimately, with this SIG, we aim to shape the future of the field of sports-HCI even further.

\section{Primary Contact}

Florian 'Floyd' Mueller, floyd@exertiongameslab.org

\section{References}

1. P. Dourish. Where the Action Is: The Foundations of Embodied Interaction. Boston, USA: MIT Press, 2001.

$2 . \quad$ C. Hummels, K. C. J. Overbeeke and S. Klooster.

Move to Get Moved: A Search for Methods, Tools and

Knowledge to Design for Expressive and Rich Movement-

Based Interaction. Personal and Ubiquitous Computing 11, 8 (2007), 677-690.

3. Lian Loke, Astrid Larssen, Toni Robertson and Jenny Edwards. Understanding Movement for Interaction Design: Frameworks and Approaches. Personal and Ubiquitous Computing 11, 8 (2007), 691-701.

4. $\quad$ M Ludvigsen, MH Fogtmann and K Gronbek. 2010

Tactowers: An Interactive Training Equipment for Elite Athletes. DIS'10. ACM, 412-415.

5. Mark McClusky. 2009. The Nike Experiment: How the Shoe Giant Unleashed the Power of Personal Metrics. http://www.wired.com/medtech/health/magazine/17-

07/lbnp_nike?currentPage $=$ all .

6 J. Moen. Kinaesthetic Movement Interaction:

Designing for the Pleasure of Motion. PhD thesis, 2006

7. F. Mueller, D. Edge, F. Vetere, M.R. Gibbs, S.

Agamanolis, B. Bongers and J.G. Sheridan. 2011.

Designing Sports: A Framework for Exertion Games. $C H I$ '11. ACM, 2651-2660.

8. Florian Mueller and Matthew Muirhead. 2015

Jogging with a Quadcopter. CHI '15. ACM, 2023-2032.

9. Stina Nylander, Jakob Tholander, Florian Mueller

and Joe Marshall. 2014. Hci and Sports. CHI '14 Extended Abstracts. ACM, 115-118.

10. Stina Nylander, Jakob Tholander, Florian Mueller and Joe Marshall. Hci and Sports. interactions 22, 2 (2015), 30-31.

11. Yvonne Rogers. Interaction Design Gone Wild:

Striving for Wild Theory. interactions 18, 4 (2011), 58-62.

12. Jakob Tholander and Stina Nylander. 2015. Snot, Sweat, Pain, Mud, and Snow: Performance and Experience in the Use of Sports Watches. CHI'15. ACM, 2913-2922.

13. R. S. Weinberg and D. Gould. Foundations of

Sport and Exercise Psychology. Human Kinetics

(Champaign, IL, USA), 2006. 